\title{
Anterior chest wall in SAPHO syndrome: magnetic resonance imaging findings
}

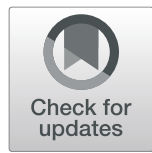

Meiyan $\mathrm{Yu}^{1 \dagger}$, Yihan $\mathrm{CaO}^{2 \dagger}$, Junqiu Li ${ }^{1 \dagger}$, Yanan Zhang ${ }^{1}$, Yuqian Ye ${ }^{3}$, Lun Wang ${ }^{3}$, Ziwei Huang ${ }^{4}$, Xinyu Lu $^{3}$, Chen $\mathrm{Li}^{5^{*}}$ (1) and Jianwei Huo ${ }^{1^{*}}$

\begin{abstract}
Background: The anterior chest wall (ACW) involvement is characteristic of synovitis, acne, pustulosis, hyperostosis, and osteitis (SAPHO) syndrome, yet little research has focused on its magnetic resonance imaging (MRI) findings.

Purpose: To characterize the MRI features of the ACW in patients with SAPHO syndrome.

Methods: Seventy-one patients with SAPHO syndrome and ACW involvement evidenced by bone scintigraphy were recruited in this cross-sectional study. The ACW region was scanned using sagittal, axial, and oblique coronal Dixon T2-weighted sequences and axial Dixon T1-weighted sequences. The characteristics of both active inflammatory and chronic structural lesions were evaluated.

Results: The ACW lesions exhibited an asymmetrical distribution and a predilection for the sternocostoclavicular region (93.0\%). Notably, $91.5 \%$ of the patients had lesions in the area of the anterior first ribs. Bone marrow edema (BME) was observed in 63 (88.7\%) patients, which mainly affected the sternocostal joints (87.3\%) and the manubrium sterni (84.5\%). All of the BMEs were distributed under the articular surface or the bone cortex, consistent with the distribution of the ligaments and joint capsules. Synovitis was detected in 64 (90.1\%) patients, with a predilection for the sternoclavicular joints (76.1\%). A soft tissue mass or infiltration was found in all the patients who had bone marrow edema. Thirteen (18.3\%) patients showed venous stenosis. Structural changes included bone bridge formation (80.3\%), hyperostosis (43.7\%), and fat infiltration (39.4\%). Four common patterns of involvement were observed: the first rib area, the sternoclavicular area, the sternal angle area, and the areas of the second to sixth sternocostal joints.
\end{abstract}

Conclusion: The ACW lesions of SAPHO syndrome demonstrated a triad of enthesitis, synovitis, and osteitis, suggesting complex interactions among the ligaments, synovium, and bones in the region. The inflammatory changes in the first rib area were highlighted in SAPHO syndrome.

Keywords: SAPHO syndrome, Magnetic resonance imaging, Anterior chest wall, Bone marrow edema, Enthesitis, Synovitis

\footnotetext{
* Correspondence: casio1981@163.com; huojw1234@sina.com

${ }^{+}$Meiyan Yu, Yihan Cao and Junqiu Li contributed equally to this work.

${ }^{5}$ Department of Traditional Chinese Medicine, Peking Union Medical College

Hospital, Peking Union Medical College and Chinese Academy of Medical

Sciences, No.1, Shuai Fu Yuan, Beijing 100730, China

'Department of Radiology, Beijing Hospital of Traditional Chinese Medicine,

Capital Medical University, Mei Shu Guan Hou Street, Beijing 100010, China

Full list of author information is available at the end of the article
}

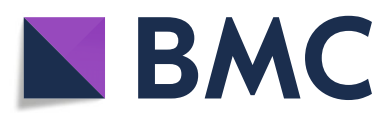

(c) The Author(s). 2020 Open Access This article is licensed under a Creative Commons Attribution 4.0 International License, which permits use, sharing, adaptation, distribution and reproduction in any medium or format, as long as you give appropriate credit to the original author(s) and the source, provide a link to the Creative Commons licence, and indicate if changes were made. The images or other third party material in this article are included in the article's Creative Commons licence, unless indicated otherwise in a credit line to the material. If material is not included in the article's Creative Commons licence and your intended use is not permitted by statutory regulation or exceeds the permitted use, you will need to obtain permission directly from the copyright holder. To view a copy of this licence, visit http://creativecommons.org/licenses/by/4.0/. The Creative Commons Public Domain Dedication waiver (http://creativecommons.org/publicdomain/zero/1.0/) applies to the data made available in this article, unless otherwise stated in a credit line to the data. 


\section{Summary statement}

The anterior chest wall involvement of SAPHO syndrome demonstrated a triad of enthesitis, synovitis, and osteitis, with prominent lesions in the first rib area.

\section{Key results}

- The lesions of the anterior chest wall exhibited an asymmetrical distribution and a predilection for the area of the anterior first ribs.

- All of the bone marrow edemas were distributed under the articular surface or the bone cortex, consistent with the distribution of the ligaments and joint capsules.

- Four common patterns of involvement were observed: the first rib area, the sternoclavicular area, the sternal angle area, and the areas of the second to sixth sternocostal joints.

SAPHO syndrome: synovitis, acne, pustulosis, hyperostosis, and osteitis syndrome

\section{Introduction}

Synovitis, acne, pustulosis, hyperostosis, and osteitis (SAPHO) syndrome, first proposed by Chamot et al. in 1987, is a spectrum of heterogeneous diseases characterized by osteoarticular and dermatological manifestations [1]. This disease is distributed globally, with an estimated annual prevalence of less than 1 in 10,000 for Caucasians and 1.44 in $1 \times 10^{8}$ in individuals of Japanese descent [2]. Diagnostic challenges may arise due to heterogeneous manifestations of the disease: either acne and arthritis or acne and anterior chest wall $(\mathrm{ACW})$ osteitis with an unclear pustulosis history [3]. The ACW is the most commonly involved site, affecting approximately $70-90 \%$ of adult patients [4-9]. The radiological findings of the osteoarticular manifestations in SAPHO syndrome play a key role in its early and correct diagnosis [10]. The typical "bull's head" change on whole-body bone scintigraphy (WBBS) is characteristic of SAPHO syndrome [4], but the frequency of the sign is low [5]. Conventional X-ray and computed tomography examinations have limited capacity in visualizing active inflammatory changes [4]. Magnetic resonance imaging (MRI) is the only method that can detect bone marrow edema (BME) and soft tissue involvement [11]. However, only a few prior reports have specifically investigated the MRI abnormalities of the ACW in SAPHO patients [12-15]. The aim of our study was to characterize the MRI findings of $\mathrm{ACW}$ involvement in SAPHO patients so as to facilitate the understanding of the imaging features and pathogenesis of the disease.

\section{Methods}

\section{Patients and clinical evaluation}

In this cross-sectional study, seventy-one patients fulfilling the diagnostic criteria for SAPHO syndrome proposed by Kahn et al. [9] were enrolled in Peking Union Medical College Hospital and Beijing Traditional Chinese Medicine Hospital from March 2018 and June 2019. All patients were aged 18-70 and had ACW involvement confirmed by WBBS using ${ }^{99 \mathrm{~m}} \mathrm{Tc}-\mathrm{MDP}$. ACW involvement was defined by abnormally increased tracer uptake in the ACW region delineated superiorly by the suprasternal notch, sternoclavicular joints (SClJs), and clavicles, inferiorly by the costal arch, and laterally by the anterior axillary line. Informed written consent was obtained from each patient.

Demographic data and clinical features were recorded, including osteoarticular symptoms and dermatological manifestations. Laboratory evaluations included erythrocyte sedimentation rate (ESR), high-sensitivity C-reactive protein (hs-CRP), rheumatoid factor (RF), anti-nuclear antibody (ANA), and human leukocyte antigen (HLA)-B27, which were measured within 3 days of MRI examination. The Ethics Committee of Beijing Hospital of Traditional Chinese Medicine, Capital Medical University, approved this study (ethics document number: 2018BL-0-050-01).

\section{MRI protocol}

MR imaging of the ACW region was performed on a Magnetom Skyra 3.0 T scanner (Siemens Healthcare, Germany). Patients were imaged in the supine position using a surface phased-array coil. Respiratory-triggered sagittal, axial, and oblique coronal T2W Turbo Spin Echo (TSE) Dixon MRI sequences were initially performed, followed by an axial T1W Dixon-Volume Interpolation Breathhold Examination (VIBE) sequence. VIBE sequence was adopted to reduce scan time as prolonged scan duration is particularly uncomfortable for SAPHO patients. Briefly, the following parameters were used for the T2W TSE Dixon sequences: repetition time (TR) $2500 \mathrm{~ms}$ and echo time (TE) $92 \mathrm{~ms}$ for sagittal images, TR $3500 \mathrm{~ms}$ and TE $92 \mathrm{~ms}$ for oblique coronal and axial images, field of view (FOV) $260 \mathrm{~mm}$, imaging matrix $205 \mathrm{~mm} \times 256 \mathrm{~mm}$, section thickness $3 \mathrm{~mm}$, and interslice gap $0.3 \mathrm{~mm}$. For the axial T1W Dixon-VIBE sequence, the parameters were TR $4.11 \mathrm{~ms}, \mathrm{TE} 1.31 \mathrm{~ms}$, FOV $380 \mathrm{~mm}$, imaging matrix $195 \times 320 \mathrm{~mm}$, section thickness $3 \mathrm{~mm}$, and interslice gap $0.3 \mathrm{~mm}$.

\section{Analysis of images}

All images were evaluated independently by two radiologists (ZYN: 6 years of MRI experience; LJQ: 25 years of MRI experience) blinded to the clinical features and bone scintigraphy at the time of their reviews. Disagreements were resolved in a consensus reading with a third experienced musculoskeletal radiologist (HJW: 28 years 
of experience). The reviewers evaluated and recorded each anatomical site in the AWC for the presence of the following features: (1) BME, defined as a hyperintense bone marrow signal on water-only T2W Dixon images on two consecutive slices. The symmetry and distribution of the lesions and the involvement of the soft tissue around the BME sites were also evaluated. (2) Synovitis, defined as the existence of high fluid accumulation signals in the joint cavity. (3) Fat infiltration, defined as bright bone marrow signals on fat-only T2W Dixon images on two consecutive slices. (4) Ossification of the costal cartilage, defined as eggshell-like continuous ossification or a wide-range ossification (see Fig. 4, as an example). (5) Hyperostosis, determined in contrast to the contralateral and surrounding bone. (6) Bone bridge, defined as an extended bone marrow signal connecting different bones [16-18]. (7) Venous stenosis, defined as a reduction in diameter compared with that of normal vessels [19].

In order to calculate the number of involved sites, we defined 18 sites in the ACW region: the SClJs, the costoclavicular ligament area (including the medial end of the clavicles), the middle and lateral region of the clavicles, the 1st sternocostal joints (SCoJs), the 2nd SCoJs and sternal angle, the 3rd SCoJs, the 4th SCoJs, the 5th SCoJs, and the 6th and 7th SCoJs. Each area was further divided into the left and right sites.

\section{Statistics}

Data were presented as numbers (\%) for categorical variables and mean (SD) for continuous variables. Agreement was expressed in Cohen's $\kappa$, positive agreement, and negative agreement. Student's $t$ test was applied to compare between groups for continuous variables. All tests were two-tailed with the significant level of 0.05 . Analyses were conducted using R 3.5.3 and SPSS 19.0.

\section{Results}

\section{Demographic and clinical characteristics}

There were 71 patients (55 women and 16 men, aged 23 to 69 years old) included in our study. The mean age of onset of osteoarticular symptoms and skin lesions were $49.0 \pm 10.6$ and $40.2 \pm 10.2$ years. The mean age of diagnosis was $44.0 \pm 12.3$ years and the mean disease duration was $51.3 \pm 9.9$ months. All patients had suffered anterior chest pain in the course of the disease. Palmoplantar pustulosis was the most common skin lesion (83.1\%), and severe acne appeared in $7.0 \%$ of patients. Only $9.9 \%$ of patients had no skin lesions. None of the patients had swelling of arm or neck or other symptoms of central venous stenosis. There were $63.4 \%$ of patients with elevated ESR or hs-CRP. The RF, ANA, and HLAB27 were positive in $7.0 \%, 2.8 \%$, and $5.6 \%$ of patients, respectively. The details are provided in Table 1.
Table 1 Demographic and clinical characteristics of the 71 patients with SAPHO syndrome

\begin{tabular}{|c|c|}
\hline \multicolumn{2}{|l|}{ Demographic and clinical characteristics $(n=71)$} \\
\hline \multicolumn{2}{|l|}{ Demographic characteristics } \\
\hline Sex, female/male & $55 / 16$ \\
\hline Age at imaging, mean (S.D.), years & $44.0(12.1)$ \\
\hline $\begin{array}{l}\text { Age at onset of osteoarticular symptoms, } \\
\text { mean (S.D.), years }\end{array}$ & $49.0(10.6)$ \\
\hline Age at onset of skin lesions, mean (S.D.), years & $40.2(10.2)$ \\
\hline Duration of disease, mean (S.D.), months & $51.3(9.9)$ \\
\hline Age at SAPHO diagnosis, mean, (S.D.), years & $44.0(12.3)$ \\
\hline Duration of diagnosis, mean (S.D.), years & $4.0(5.0)$ \\
\hline \multicolumn{2}{|l|}{ Clinical characteristics, number (\%) } \\
\hline Anterior chest pain & $71(100.0)$ \\
\hline Spinal or sacroiliac pain & $52(73.2)$ \\
\hline Peripheral skeletal pain & $41(57.7)$ \\
\hline \multicolumn{2}{|l|}{ Skin manifestations } \\
\hline None & $7(9.9)$ \\
\hline Palmoplantar pustulosis & $59(83.1)$ \\
\hline Severe acne & $5(7.0)$ \\
\hline \multicolumn{2}{|l|}{ Laboratory findings } \\
\hline ESR, median (range), $\mathrm{mm} / \mathrm{h}$ & $17(2-91)$ \\
\hline hs-CRP, median (range), g/l & $4.24(0.41-57.63)$ \\
\hline ESR or hs-CRP elevated, number (\%) & $45(63.4)$ \\
\hline ANA positive, number (\%) & $5(7.0)$ \\
\hline RF positive, number (\%) & $2(2.8)$ \\
\hline HLA-B27 positive, number (\%) & $4(5.6)$ \\
\hline \multicolumn{2}{|l|}{ Whole-body bone scintigraphy } \\
\hline Anterior chest wall & $71(100)$ \\
\hline Spine & $43(60.6)$ \\
\hline Sacroiliac joint & $28(39.4)$ \\
\hline Peripheral skeleton & $22(31.0)$ \\
\hline Skull & $9(12.7)$ \\
\hline Pelvis & $3(4.2)$ \\
\hline
\end{tabular}

ESR erythrocyte sedimentation rate, $h s$-CRP high-sensitivity C-reactive protein, ANA antinuclear antibody, RF rheumatoid factor, HLA-B27 human leukocyte antigen-B27

\section{MRI findings of $\mathrm{ACW}$}

The agreement between the two readers (ZYN and LJQ) was sufficient. Among the 55 independent variables of MRI features, 48 (87.3\%) variables had an interrater agreement $\geq 0.7$ between ZYN and LJQ and 7 (12.7\%) had an interrater agreement 0.6 to 0.7 (see Supplementary 1).

All 71 patients exhibited abnormalities on ACW MRI. On average, $4.8 \pm 3.4$ sites were involved per patient with a median of 4 and a range of 1 to 17 . Male patients tended to have more involved sites than female patients though the difference was not statistically significant (6.1 \pm 4.0 vs. $4.4 \pm 3.1, P=0.061)$. The lesions exhibited a 
mixture of active (inflammatory) and chronic (structural) changes, with an asymmetrical distribution and a predilection for the sternocostoclavicular region (93.0\%), including the SClJs (76.1\%) and the sternocostal joints (69\%). For patients with lesions in all the three areas (sternal, costal, and clavicular regions), unilateral involvement was predominant, with $24(33.8 \%)$ and 19 (26.8\%) cases on the left and right side, respectively. Bilateral lesions were only seen in $13(18.3 \%)$ patients. Notably, 91.5\% patients had lesions in the anterior first rib and its surrounding soft tissue.

\section{$B M E$}

BME, which indicated acute inflammation, was observed in $63(88.7 \%)$ patients. Affected sites included the manubrium sterni $(60,84.5 \%)$, sternal angle $(26,36.6 \%)$, mesosternum $(11,15.5 \%)$, clavicle $(35,49.3 \%)$, and second rib (2, $2.8 \%$ ). All the involved sites showed signs of inflammation in the surrounding soft tissues. As for the joints, the most commonly affected sites were the SCoJs (87.3\%), followed by the $\mathrm{SCl} J \mathrm{~s}$ (38.0\%). Extended BME involving the sternum and bilateral SClJs (resembling the "bull's head" sign on bone scintigraphy) was revealed in only $3(4.2 \%)$ patients. All of the BMEs were distributed under the articular surface or the cortex, consistent with the distribution of ligaments and joint capsules (Table 2 and Fig. 1 a, b, e). Four common patterns of involvement were observed (Fig. 2): (I) the first rib area, possibly developing from the anterior end of the first rib to the first $\mathrm{SCOJ}$ and the costoclavicular ligament; (II) the sternoclavicular area, involving the $\mathrm{SCl}$, the medial end of the clavicle, and the interclavicular ligament; (III) the sternal angle area; and (IV) the areas of the second to sixth SCoJs.

\section{Synovitis}

Joint effusion on MR images was recognized in 64 (90.1\%) patients, with a predilection for the SClJs (76.1\%), followed by the SCoJs (15.5\%), including the first $\mathrm{SCOJ}(2.8 \%)$. Joint effusion was also found in the manubriosternal joint (MSJ) (7.0\%), which was reported to be a synovial joint in $\sim 30 \%$ of patients [20] (Table 2 and Fig. $1 \mathrm{f}, \mathrm{g}, \mathrm{h}$ ).

\section{Soft tissue involvement}

A soft tissue mass or infiltration was observed in all the patients who had BME, among which 49 (69.0\%) patients exhibited a retrosternal tumor-like appearance. We found 16 (22.5\%) patients with edema in the pectoralis major, most in diffused directions or in the direction of the myofibers. Venous stenosis was identified in 13 (18.3\%) patients, including the right $(6,8.8 \%)$ and left (12, 16.9\%) brachiocephalic veins (Fig. 1 h, i and Fig. 3).
Table 2 Active lesions in the anterior chest wall detected by MRI in the 71 patients with SAPHO syndrome

\begin{tabular}{|c|c|}
\hline Active lesions & Number (\%) \\
\hline \multicolumn{2}{|l|}{ Bone marrow edema } \\
\hline Sternoclavicular joint & $27(38.0)$ \\
\hline Left only & $9(12.7)$ \\
\hline Right only & $6(8.5)$ \\
\hline Bilateral & $12(16.9)$ \\
\hline Sternocostal joint & $62(87.3)$ \\
\hline Left only & $7(9.9)$ \\
\hline Right only & $12(16.9)$ \\
\hline Bilateral & $43(60.6)$ \\
\hline 1 st & $38(53.5)$ \\
\hline 2nd to 6th & $11(15.5)$ \\
\hline Clavicle & $35(49.3)$ \\
\hline Medial end, left only/right only/bilateral & $11(15.5) / 8(11.3) / 16(22.5)$ \\
\hline $\begin{array}{l}\text { Middle and lateral region, left only/right } \\
\text { only/bilateral }\end{array}$ & $1(1.4) / 1(1.4) / 0(0)$ \\
\hline \multicolumn{2}{|l|}{ Sternum } \\
\hline Manubrium sterni & $60(84.5)$ \\
\hline $\begin{array}{l}\text { Region next to the clavicle and the } \\
\text { first rib }\end{array}$ & $54(76.1)$ \\
\hline Left only/right only/bilateral & $10(14.1) / 9(12.7) / 35(49.3)$ \\
\hline Sternal angle & $26(36.6)$ \\
\hline Mesosternum & $11(15.5)$ \\
\hline Region next to the 3 rd ribs & $8(11.3)$ \\
\hline Region next to the 4 th ribs & $7(9.9)$ \\
\hline Region next to the 5 th ribs & $6(8.5)$ \\
\hline Region next to the $6-8$ th ribs & $7(9.9)$ \\
\hline Xiphoid & $3(4.2)$ \\
\hline \multicolumn{2}{|l|}{ Synovitis } \\
\hline Sternoclavicular joint & $54(76.1)$ \\
\hline Left only/right only & $4(5.6) / 8(11.3)$ \\
\hline Bilateral & $43(60.6)$ \\
\hline $\begin{array}{l}\text { Narrowing of joint space, left only/ } \\
\text { right only/bilateral }\end{array}$ & $1(1.4) / 2(2.8) / 8(11.3)$ \\
\hline $\begin{array}{l}\text { Pseudowidening of joint space, left } \\
\text { only/right only/bilateral }\end{array}$ & $2(2.8) / 1(1.4) / 7(9.9)$ \\
\hline Manubriosternal joint & $5(7.0)$ \\
\hline Sternocostal joint & $11(15.5)$ \\
\hline 1st, left only/right only/bilateral & $0(0) / 0(0) / 2(2.8)$ \\
\hline 2nd, left only/right only/bilateral & $2(2.8) / 2(2.8) / 7(9.9)$ \\
\hline 3rd, left only/right only/bilateral & $1(1.4) / 4(5.6) / 5(7.0)$ \\
\hline 4-6th, left only/right only/bilateral & $0(0) / 0(0) / 4(5.6)$ \\
\hline
\end{tabular}

\section{Findings of the first ribs}

In our patients, the manifestation of the first ribs was interesting and is therefore elaborated here specifically. 

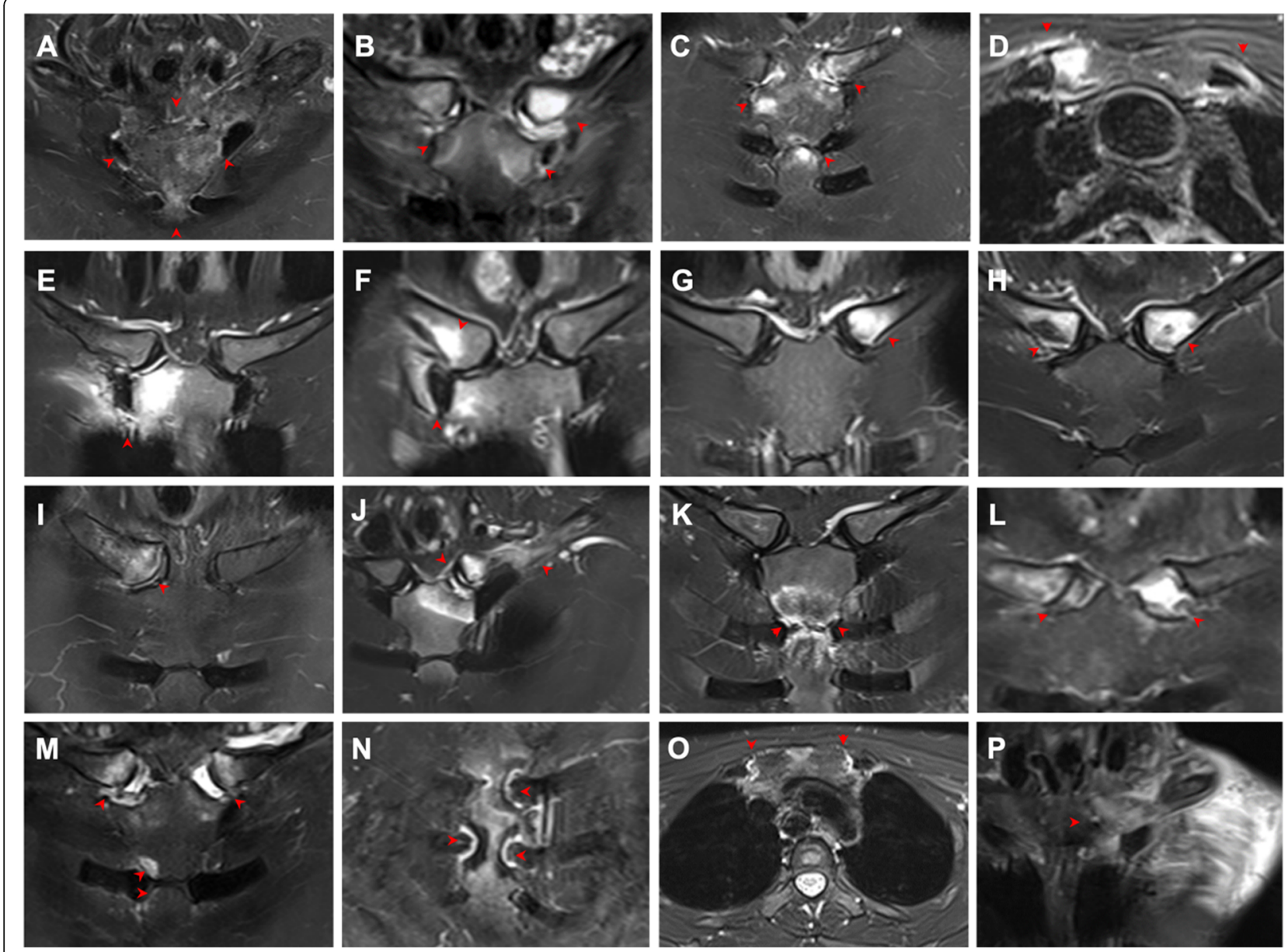

Fig. 1 Active inflammatory lesions in the ACW shown by oblique coronal $(\mathbf{a}-\mathbf{c}, \mathbf{e}-\mathbf{n}, \mathbf{p})$ and axial $(\mathbf{d}, 0)$ water-only T2W Dixon images in patients with SAPHO syndrome. $\mathbf{a}$ Extended BME in the bilateral sternoclavicular region, resembling the "bull's head" sign. $\mathbf{b}$ BME of the

sternocostoclavicular region. $\mathbf{c}$ BME of the sternocostoclavicular region and the sternal angle. $\mathbf{d}$ BME of the ossified bones in the first left rib and the first right SCOJ. e Active inflammatory changes of the surrounding tissue of the first right rib and the first right SCoJ. $\mathbf{f}$ Active inflammatory changes of the right costoclavicular ligament area and the first right SCoJ. $\mathbf{g}$ BME of the medial end of the left clavicle. $\mathbf{h}$ BME of the medial ends of the bilateral clavicles. i BME and hyperostosis of the medial end of the right clavicle. $\mathbf{j}$ Active inflammatory changes of the left costoclavicular ligament area and the SCIJ. $\mathbf{k}$ BME of the sternal angle. I Pseudowidening of the SCIJ. $\mathbf{m}$ BME of the bilateral SCIJs with pseudowidening of joint space and BME of the right side of the sternal angle. $\mathbf{n}$ Joint effusion in the bilateral second and third SCoJ. $\mathbf{o}$ Joint effusion in the bilateral first SCOJ and soft tissue mass behind the manubrium sterni. p Soft tissue infiltration in the chest wall. Lesions are indicated by red arrows. BME, bone marrow edema; SCOJ, sternocostal joint; SCIJ, sternoclavicular joint

Sixty-five (91.5\%) patients had lesions in the anterior first ribs and the surrounding soft tissue. Thirty-seven (52.1\%) patients had different degrees of ossification in the first rib, with $8(11.3 \%)$ and $11(15.5 \%)$ cases on the left and right side, respectively. Bilateral ossification was observed in 18 (25.4\%) patients. Notably, 70\% of ossified first ribs had BME, $22 \%$ had fat infiltration, and $50 \%$ had asymmetrical hyperostosis (Fig. 4).

\section{Chronic structural lesions}

Different types of chronic lesions were detected. Bone bridges were observed in $80.3 \%$ patients, hyperostosis in $43.7 \%$ patients, and fat infiltration in $39.4 \%$ patients. Hyperostosis was widespread, observed in the clavicle (26.8\%), manubrium sterni (31.0\%), sternal angle (31.0\%), and mesosternum (8.5\%). Fat infiltration was distributed widely in the manubrium sterni (38.0\%) and mesosternum (12.7\%). There were different shapes of fat infiltration, such as crescent (9.9\%), sheet (14.1\%) and scatter (31\%) (Table 3 and Fig. 5).

\section{Discussion}

The ACW is the most predominantly involved area of SAPHO syndrome in adults. MRI enables the detection of both active (inflammatory) and chronic (structural) changes in this region with a high sensitivity and level of detail $[4,20,21]$. 

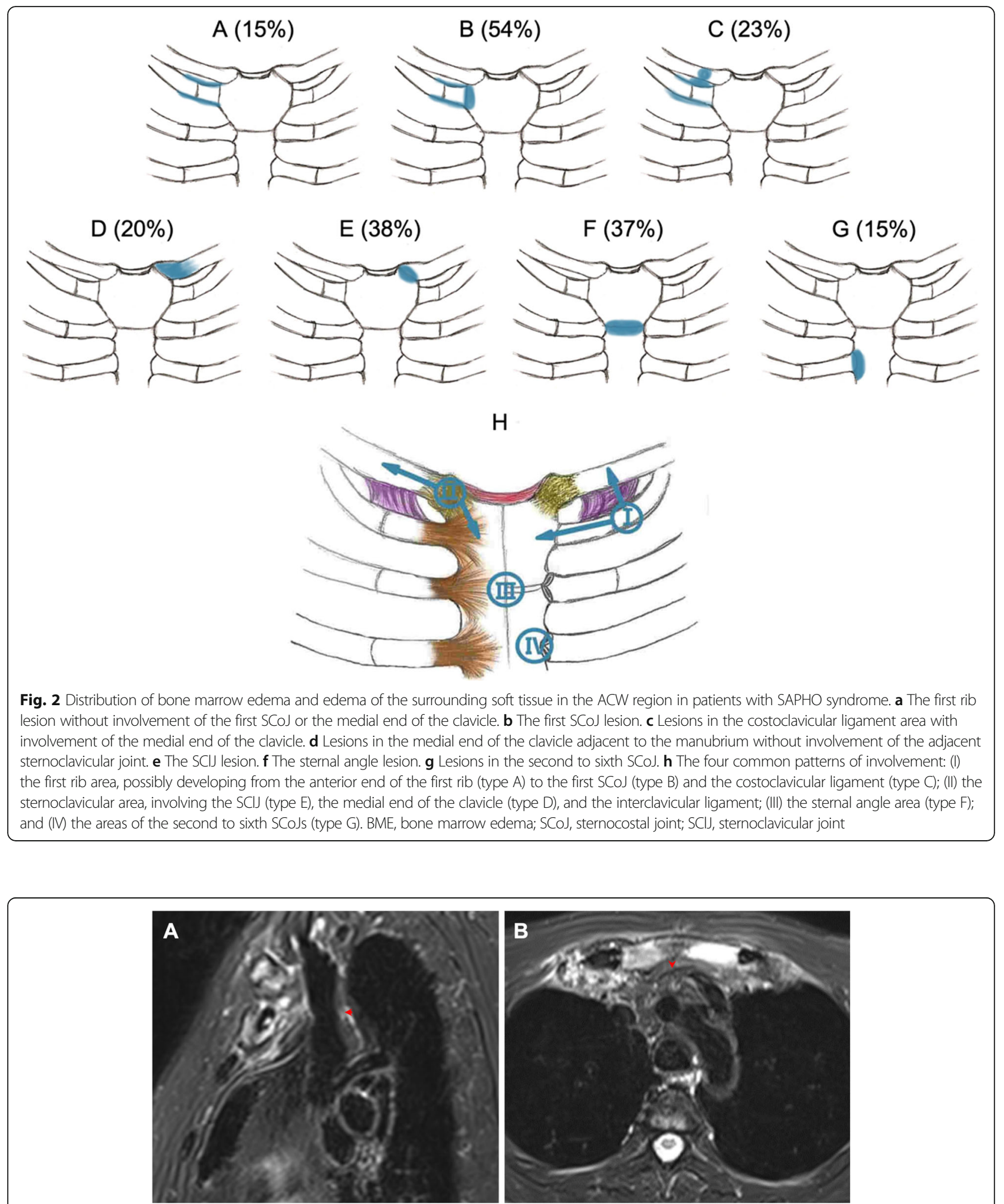

Fig. 3 Soft tissue mass in the ACW region. a Sagittal water-only T2W Dixon image shows a soft tissue mass or infiltration around the hyperostotic bones in a 55-year-old female with a disease duration of 60 months. The lower part of the superior vena cava was normal, but the right brachiocephalic vein behind the soft tissue mass was slightly narrowed (red arrow). b Axial water-only T2W Dixon image reveals a soft tissue mass or infiltration behind the manubrium sterni in a 49-year-old male with a disease duration of 6 months. The left brachiocephalic vein was surrounded by the soft tissue mass and could not be evaluated (red arrow) 

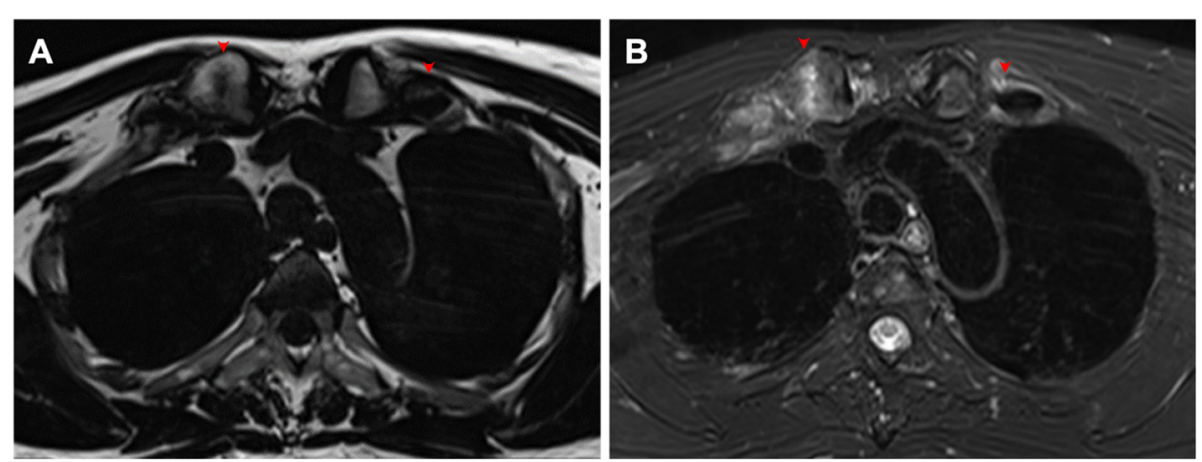

Fig. 4 Lesions of the first costal cartilage in a 43-year-old female with SAPHO syndrome. a Axial fat-only T2W Dixon image shows irregular hyperintensity in the ossified bones in the right first costal cartilage, indicating fat infiltration. b Axial water-only T2W Dixon image shows irregular ossification beneath the perichondrium of the bilateral first costal cartilage and hyperintensity in the surrounding soft tissue, indicating inflammation. Lesions are indicated by red arrows

Table 3 Chronic lesions in the anterior chest wall detected by MRI in the 71 patients with SAPHO syndrome

\begin{tabular}{ll}
\hline Chronic lesions & Number (\%) \\
\hline Bone bridge & $57(80.3)$ \\
Costoclavicular ligament & $11(15.5)$ \\
Left only & $0(0)$ \\
Right only & $4(5.6)$ \\
Bilateral & $7(9.9)$ \\
Radiate sternocostal ligament (the 1st rib) & $55(77.5)$ \\
Left only & $1(1.4)$ \\
Right only & $1(1.4)$ \\
Bilateral only & $53(74.6)$ \\
Sternoclavicular ligament & $11(15.5)$ \\
Left only & $0(0)$ \\
Right only & $4(5.6)$ \\
Bilateral & $7(9.9)$ \\
Sternal angle & $17(23.9)$ \\
Hyperostosis & $31(43.7)$ \\
Clavicle & $19(26.8)$ \\
Left only & $2(2.8)$ \\
Right only & $7(9.9)$ \\
Bilateral & $10(14.1)$ \\
Manubrium sterni & $22(31.0)$ \\
Sternal angle & $22(31.0)$ \\
Mesosternum & $6(8.5)$ \\
Manubrium sterni & $28(39.4)$ \\
Mesosternum & $27(38.0)$ \\
\hline & $9(12.7)$ \\
\hline
\end{tabular}

Any areas of the ACW can be affected, but the sternoclavicular, manubriosternal, and sternocostal joints are the most commonly involved sites according to previous studies $[4,9,11,22]$. In our study, the most frequently involved sites were the $\mathrm{SClJ}$ and the first rib area. Such findings were consistent with a study by Cao et al. based on ${ }^{99 \mathrm{~m}}$ Tc-MDP WBBS [5].

The pathogenesis and evolvement of ACW lesions in SAPHO syndrome remains unclear. The osteoarticular changes in the ACW were subdivided into three stages based on conventional radiography [23]. Stage 1 is mild ossification localized to the costoclavicular ligament. Stage 2 is generalized ossification of the sternocostoclavicular region. Stage 3 is a further progression of the hyperostotic changes, involving the superior margin of the clavicle. This development suggests a disease primarily involving entheses, particularly at the costoclavicular ligament, that spreads to the adjacent joints and bones. However, changes may also begin in the bones, often in the manubrium sterni, and spread to the joints and surrounding capsular and ligamentous structures [6]. Two theories (inflammatory enthesitis and reactive osteitis elicited by slow microorganism infection) regarding the pathology of the disease have also been proposed [24].

Our study identified several characteristics of ACW lesions on MRI that might unveil the pathogenic process of SAPHO syndrome. First, a triad of enthesitis, synovitis, and osteitis was demonstrated. Ligamentous involvement was directly evidenced by bone bridge formations along the ligaments. Second, all of the BMEs were distributed under the articular surface or the cortex, consistent with the distribution of ligaments and joint capsules. The BMEs seem to involve any area attached to ligaments and synovial joints, not necessarily initiating from the costoclavicular ligament as proposed by Sonozaki et al. [20]. Given that all the BMEs were related to the insertion sites of the 

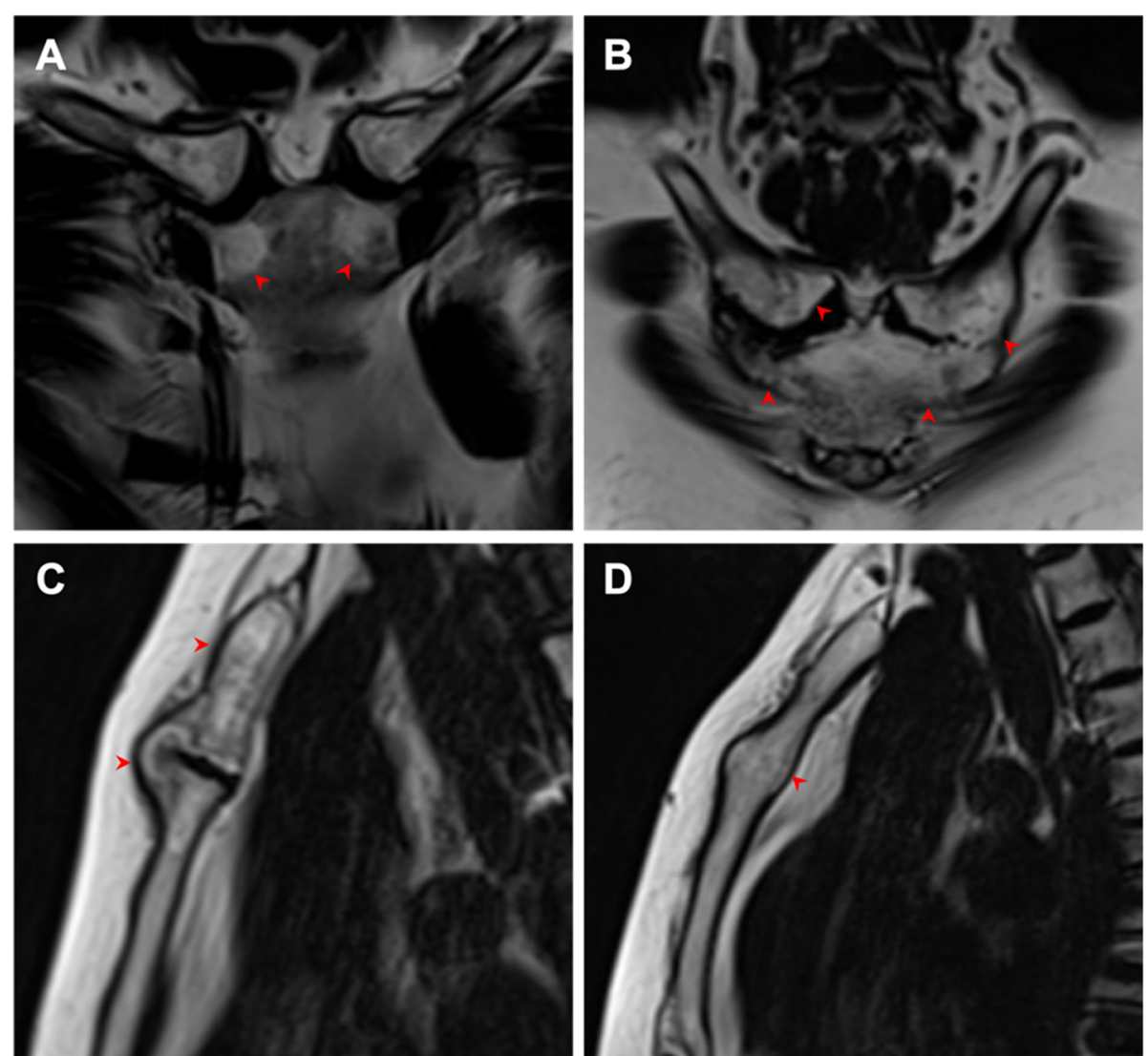

Fig. 5 Chronic lesions in the ACW shown by oblique coronal (a-c) and sagittal (d, e) T2W Dixon images in patients with SAPHO syndrome. a Fat-only T2W Dixon image shows different shapes of fat infiltration, such as crescent in the corners of the manubrium, sheet in the right clavicle, and scattered lesions in the left clavicle. $\mathbf{b}$ Fat-only T2W Dixon image shows ossification of the costoclavicular ligament. c Fat-only T2W Dixon image shows a bone bridge of the sternal angle. $\mathbf{d}$ Fat-only T2W Dixon image shows hyperostosis in the sternal angle. Lesions are indicated by red arrows

ligaments and joint capsules, we speculate that enthesitis might be the primary disorder. Similar findings were observed in studies on spinal MRI and CT, which indicate that vertebral involvement in SAPHO syndrome may be triggered by vertebral corner lesions originating from the enthesitis at the junction of the outer fibers of the annulus fibrosis and vertebral epiphyseal ring [24, 25].

Why were the first rib area and the SClJs the most commonly affected sites in the ACW? Anatomically, the first costal cartilage can ossify in adolescence, so the internal environment is relatively complex [26, 27]. In addition, the costoclavicular ligaments and the radiate sternocostal ligaments are related to the first ribs [28]. The SClJ, a true diarthrodial synovial joint, has attachments to three complex ligaments (the interclavicular ligament, anterior sternoclavicular ligament, and posterior sternoclavicular ligament) [28]. However, synovitis of the ACW has been rarely reported [29]. In our study, $90.1 \%$ of patients showed effusion in the joint cavities, although some of the manifestation may be physiological effusions, which should be proved by enhanced MRI [30,
31]. In addition, the sternal angle, which is in the vicinity of the second $\mathrm{SCoJ}$ (containing an interarticular ligament and two synovial membranes) and contains the manubriosternal joint (containing dorsal and ventral ligaments and classified as a synovial joint in $\sim 30 \%$ patients [20]), was the third-most frequently involved site.

In summary, the complex anatomical structure in the $\mathrm{ACW}$ region may contribute to the patterns of lesions in SAPHO syndrome on MRI. BME can affect any site related to ligaments and synovial joints in solitary or mixed patterns (Fig. $2 \mathrm{a}-\mathrm{g}$ ). We observed four common patterns of involvement (Fig. $2 \mathrm{~h}$ ): the first rib area, the sternoclavicular area, the sternal angle area, and the areas of the second to sixth SCoJ. These patterns can occur alone or in combinations. Further longitudinal follow-up studies are needed to investigate the evolvement of these lesions.

Structural changes may occur during periods of remission, when bone erosion tends to heal with sclerosis and periosteal new bone formation [6, 11]. Such changes are best revealed by CT imaging. In our study, 
we preliminarily evaluated hyperostosis and bone bridges using MRI. Further validation of the results on $\mathrm{CT}$ is needed. We also found that fat infiltration was widely distributed with various shapes in the ACW region, which was considered to develop from BME during remission periods [7].

Inflammatory involvement of adjacent soft tissue was often present. Studies have emphasized that voluminous soft tissue may compress or obstruct the subclavian vein, causing thoracic outlet syndrome [8,32, 33]. Our analysis found that 13 patients had stenosis of the brachiocephalic veins, all of whom were asymptomatic. As non-enhanced images were not suitable for vascular evaluation, the severity of the stenosis was not assessed. Furthermore, the pectoralis major showed obvious edema, which may mimic an aggressive process such as lymphoma or other malignancies. However, there was no delineated soft tissue mass or signs suggesting abscess formation.

There were some limitations to our study. First, there was no control group. Some other diseases may involve the ACW, such as osteoarthritis, septic arthritis, and other inflammatory conditions [20, 34]. Inclusion of control groups may help with better interpretation of the findings in SAPHO syndrome. Second, the noncontrast-enhanced MRI could not show all the involved veins, such as subclavian veins. The sensitivity and specificity for identifying synovitis and tenosynovitis are also lower using T2-weighted sequences alone compared with contrast-enhanced images [30]. Third, there was no computed tomography serving as a reference to accurately assess ossification of the costal cartilage and ligaments. Fourth, the patients were heterogeneous in terms of disease duration and treatment. Most patients had a complex medical history and treatment process, which may lead to heterogeneous manifestations [15]. Last, future studies should incorporate patient reported outcomes (such as magnitude of pain and upper extremity function) to better understand the clinical relevance of the MRI findings.

\section{Conclusions}

The ACW lesions of SAPHO syndrome demonstrated a triad of enthesitis, synovitis, and osteitis, suggesting complex interactions among the ligaments, synovium, and bones in the region. The inflammatory changes in the first rib area were highlighted in SAPHO syndrome.

\section{Supplementary information}

Supplementary information accompanies this paper at https://doi.org/10. 1186/s13075-020-02309-6.

Additional file 1: Supplementary 1. Interrater agreement of the MRI features.

\section{Authors' contributions}

$M Y, Y C$, and $J L$ are co-first authors and contributed equally to work. MY, $C L$, $Y C, J L$ and $J H$ participated in the design of the study. $Y Z, J L$, and $J H$ assessed the MR images. $C L, L W, Y C, Y Y$, and $X L$ contributed to clinical data collection. $M Y, Y C$, and ZH contributed to the analysis and interpretation of data. MY and YC wrote the manuscript. All authors revised the article critically for important intellectual content, and approved the final version to be published. The author(s) read and approved the final manuscript.

\section{Funding}

This work was supported by the CAMS Innovation Fund for Medical Sciences [2017-I2M-3001], the Capital Medical Research and Development Fund [20164-40112], and the National Key Research and Development Program of China [2016YFC0901500].

Competing interests

All the authors disclosed no relevant relationships.

\section{Author details}

${ }^{1}$ Department of Radiology, Beijing Hospital of Traditional Chinese Medicine, Capital Medical University, Mei Shu Guan Hou Street, Beijing 100010, China. ${ }^{2}$ Department of Radiology, Peking Union Medical College Hospital, Peking Union Medical College and Chinese Academy of Medical Sciences, Beijing 100730, China. ${ }^{3}$ Institute of Clinical Medicine, Peking Union Medical College and Chinese Academy of Medical Sciences, Beijing 100730, China. ${ }^{4}$ School of Traditional Chinese Medicine, Beijing University of Traditional Chinese Medicine, Beijing 100029, China. ${ }^{5}$ Department of Traditional Chinese Medicine, Peking Union Medical College Hospital, Peking Union Medical College and Chinese Academy of Medical Sciences, No.1, Shuai Fu Yuan, Beijing 100730, China.

Received: 30 June 2020 Accepted: 1 September 2020

Published online: 14 September 2020

\section{References}

1. Chamot AM, Benhamou CL, Kahn MF, Beraneck L, Kaplan G, Prost A. Acne-pustulosis-hyperostosis-osteitis syndrome. Results of a national survey. 85 cases. Revue du rhumatisme et des maladies osteoarticulaires. 1987;54(3):187-96.

2. Rukavina I. SAPHO syndrome: a review. J Child Orthop. 2015;9(1):19-27.

3. Rozin AP. SAPHO syndrome: is a range of pathogen-associated rheumatic diseases extended? Arthritis Res Ther. 2009:11(6):131.

4. Schaub S, Sirkis HM, Kay J. Imaging for synovitis, acne, pustulosis, hyperostosis, and osteitis (SAPHO) syndrome. Rheum Dis Clin N Am. 2016; 42(4):695-710

5. Cao Y, Li C, Yang Q, Wu N, Xu P, Li Y, et al. Three patterns of osteoarticular involvement in SAPHO syndrome: a cluster analysis based on whole body bone scintigraphy of 157 patients. Rheumatology (Oxford). 2019;58(6):1047-55.

6. Jurik AG, Klicman RF, Simoni P, Robinson P, Teh J. SAPHO and CRMO: the value of imaging. Semin Musculoskelet Radiol. 2018;22(2):207-24.

7. Depasquale R, Kumar N, Lalam RK, Tins BJ, Tyrrell PN, Singh J, et al. SAPHO: what radiologists should know. Clin Radiol. 2012;67(3):195-206.

8. Hayem G, Bouchaud-Chabot A, Benali K, Roux S, Palazzo E, SilbermannHoffman O, et al. SAPHO syndrome: a long-term follow-up study of 120 cases. Semin Arthritis Rheum. 1999;29(3):159-71.

9. MF K, MA K. The SAPHO syndrome. Baillieres Clin Rheumatol. 1994;8(2): $333-62$.

10. Boutin RD, Resnick D. The SAPHO syndrome: an evolving concept for unifying several idiopathic disorders of bone and skin. AJR Am J Roentgenol. 1998;170(3):585-91.

11. Earwaker JW, Cotten A. SAPHO: syndrome or concept? Imaging findings Skeletal Radiol. 2003;32(6):311-27.

12. Jurik A, Egund N. MRI in chronic recurrent multifocal osteomyelitis. Skelet Radiol. 1997;26(4):230-8.

13. Girschick H, Krauspe R, Tschammler A, Huppertz H. Chronic recurrent osteomyelitis with clavicular involvement in children: diagnostic value of different imaging techniques and therapy with non-steroidal antiinflammatory drugs. Eur J Pediatr. 1998;157(1):28-33. 
14. Falip C, Alison M, Boutry N, Job-Deslandre C, Cotten A, Azoulay R, et al. Chronic recurrent multifocal osteomyelitis (CRMO): a longitudinal case series review. Pediatr Radiol. 2013;43(3):355-75.

15. Su C, Shen Y, Liao H, Tsai C. SAPHO syndrome with enthesopathy. BMJ Case Rep. 2019;12(1):e225929.

16. Weber U, Lambert RG, Rufibach K, Maksymowych WP, Hodler J, Zejden A, et al. Anterior chest wall inflammation by whole-body magnetic resonance imaging in patients with spondyloarthritis: lack of association between clinical and imaging findings in a cross-sectional study. Arthritis Res Ther. 2012;14(1):R3.

17. Lambert RG, Bakker PA, van der Heijde D, Weber U, Rudwaleit M, Hermann $K G$, et al. Defining active sacroiliitis on MRI for classification of axial spondyloarthritis: update by the ASAS MRI working group. Ann Rheum Dis. 2016;75(11):1958-63.

18. Rudwaleit M, Jurik AG, Hermann KG, Landewe R, van der Heijde $D$, Baraliakos $X$, et al. Defining active sacroiliitis on magnetic resonance imaging (MRI) for classification of axial spondyloarthritis: a consensual approach by the ASAS/OMERACT MRI group. Ann Rheum Dis. 2009;68(10): $1520-7$.

19. Suzuki M, Kanazawa H, Shinozaki T, Sugimoto H. Radiologists need to be aware of secondary central venous stenosis in patients with SAPHO syndrome. Eur Radiol. 2017:27(11):4532-7.

20. Rennie WJ, Jans L, Jurik AG, Sudol-Szopinska I, Schueller-Weidekamm C, Eshed I. Anterior chest wall in axial spondyloarthritis: imaging, interpretation, and differential diagnosis. Semin Musculoskelet Radiol. 2018;22(2):197-206.

21. Dheer S, Zoga AC, Morrison WB. Clavicular avulsion of the costoclavicular (rhomboid) ligament: MRI findings. Radiol Case Rep. 2011;6(4):579.

22. Dihlmann W, Dihlmann SW. Acquired hyperostosis syndrome: spectrum of manifestations at the sternocostoclavicular region. Radiologic evaluation of 34 cases. Clin Rheumatol. 1991;10(3):250-63.

23. Sonozaki H, Azuma A, Okai K, Nakamura K, Fukuoka S, Tateishi A, et al. Clinical features of 22 cases with "inter-sterno-costo-clavicular ossification". A new rheumatic syndrome. Archives of orthopaedic and traumatic surgery. Archiv fur orthopadische und Unfall-Chirurgie. 1979;95:13-22.

24. Xu W, Li C, Zhao X, Lu J, Li L, Wu N, et al. Whole-spine computed tomography findings in SAPHO syndrome. J Rheumatol. 2017;44(5):648-54.

25. Laredo JD, Vuillemin-Bodaghi V, Boutry N, Cotten A, Parlier-Cuau C. SAPHO syndrome: MR appearance of vertebral involvement. Radiology. 2007;242(3): 825-31.

26. Milenkovic P, Djuric M, Milovanovic P, Djukic K, Zivkovic V, Nikolic S. The role of $C T$ analyses of the sternal end of the clavicle and the first costal cartilage in age estimation. Int J Legal Med. 2014;128(5):825-39.

27. Bahrami S, Plate U, Dreier R, DuChesne A, Willital GH, Bruckner P. Endochondral ossification of costal cartilage is arrested after chondrocytes have reached hypertrophic stage of late differentiation. Matrix Biol. 2001; 19(8):707-15.

28. Standring S. Gray's anatomy e-book: the anatomical basis of clinical practice: Elsevier Health Sciences; 2015.

29. Li C, Zuo Y, Wu N, Li L, Li F, Zhang W, et al. Synovitis, acne, pustulosis, hyperostosis and osteitis syndrome: a single centre study of a cohort of 164 patients. Rheumatology (Oxford). 2016;55(6):1023-30.

30. Rubin DA. MRI and ultrasound of the hands and wrists in rheumatoid arthritis. I. Imaging findings. Skeletal Radiol. 2019;48(5):677-95.

31. McQueen FM. The MRI view of synovitis and tenosynovitis in inflammatory arthritis: implications for diagnosis and management. Ann N Y Acad Sci. 2009;1154:21-34.

32. Cotten A, Flipo RM, Mentre A, Delaporte E, Duquesnoy B, Chastanet P. SAPHO syndrome. Radiographics. 1995;15(5):1147-54.

33. van Holsbeeck M, Martel W, Dequeker J, Favril A, Gielen J, Verschakelen J, et al. Soft tissue involvement, mediastinal pseudotumor, and venous thrombosis in pustulotic arthro-osteitis. A study of eight new cases. Skeletal Radiol. 1989;18(1):1-8.

34. Edwin J, Ahmed S, Verma S, Tytherleigh-Strong G, Karuppaiah K, Sinha J. Swellings of the sternoclavicular joint: review of traumatic and nontraumatic pathologies. EFORT Open Rev. 2018;3(8):471-84.

\section{Publisher's Note}

Springer Nature remains neutral with regard to jurisdictional claims in published maps and institutional affiliations.

Ready to submit your research? Choose BMC and benefit from:

- fast, convenient online submission

- thorough peer review by experienced researchers in your field

- rapid publication on acceptance

- support for research data, including large and complex data types

- gold Open Access which fosters wider collaboration and increased citations

- maximum visibility for your research: over $100 \mathrm{M}$ website views per year

At $\mathrm{BMC}$, research is always in progress.

Learn more biomedcentral.com/submissions 